Provided for non-commercial research and education use. Not for reproduction, distribution or commercial use.

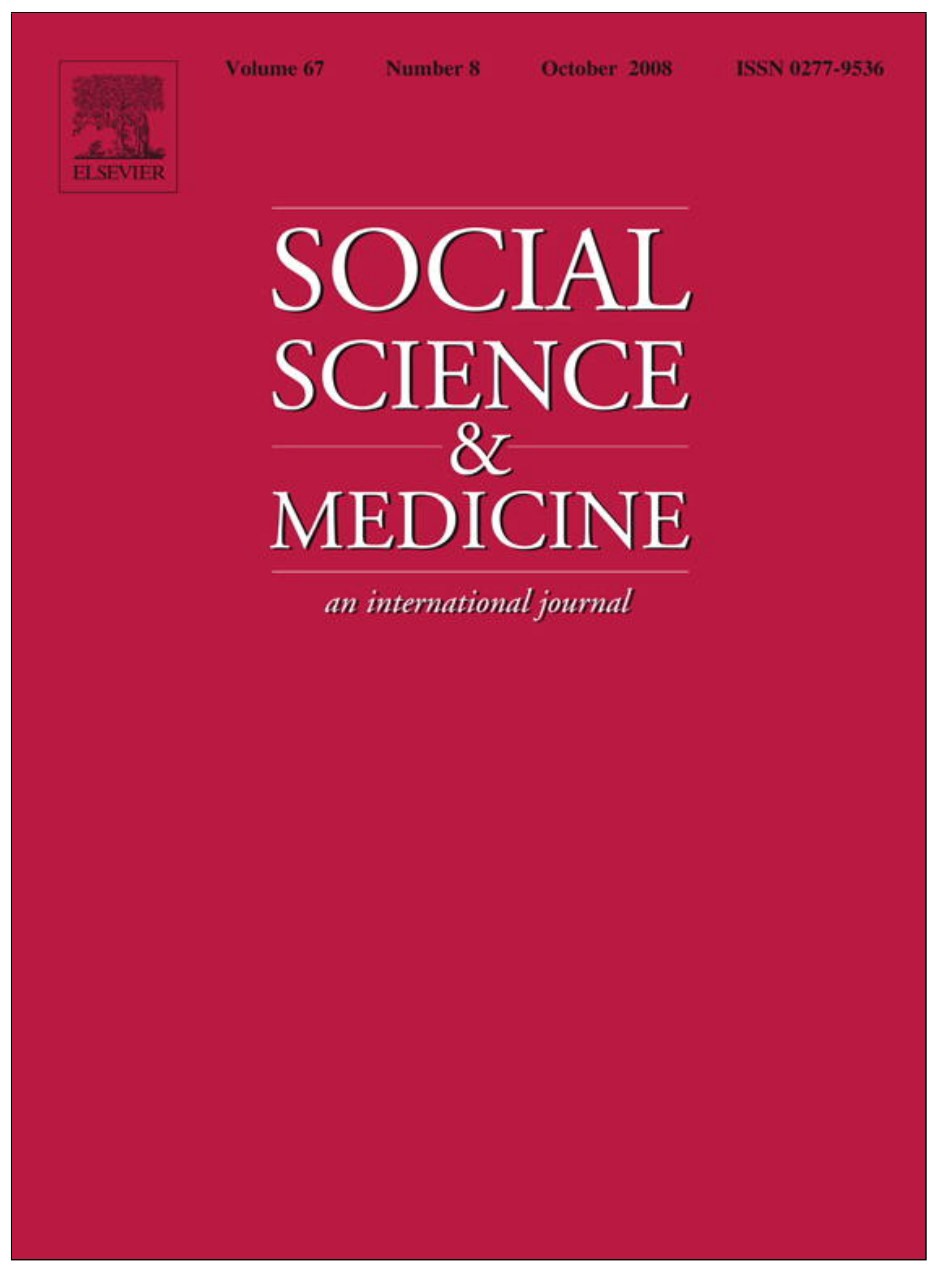

This article appeared in a journal published by Elsevier. The attached copy is furnished to the author for internal non-commercial research and education use, including for instruction at the authors institution and sharing with colleagues.

Other uses, including reproduction and distribution, or selling or licensing copies, or posting to personal, institutional or third party websites are prohibited.

In most cases authors are permitted to post their version of the article (e.g. in Word or Tex form) to their personal website or institutional repository. Authors requiring further information regarding Elsevier's archiving and manuscript policies are encouraged to visit:

http://www.elsevier.com/copyright 


\title{
The psychological impact of the Israel-Hezbollah War on Jews and Arabs in Israel: The impact of risk and resilience factors ${ }^{\text {ts }}$
}

\author{
Patrick A. Palmieri ${ }^{\mathrm{a}, \mathrm{e}, *}$, Daphna Canetti-Nisim ${ }^{\mathrm{b}}$, Sandro Galea ${ }^{\mathrm{c}}$, Robert J. Johnson ${ }^{\mathrm{d}}$, \\ Stevan E. Hobfoll ${ }^{\mathrm{e}}$ \\ a Summa Health System, Psychiatry, St. Thomas Hospital, 4th Floor, Ambulatory Care Building, 444 North Main Street, Akron, OH 44310, USA \\ ${ }^{\mathrm{b}}$ University of Haifa, Haifa, Israel \\ ${ }^{\mathrm{c}}$ University of Michigan, Ann Arbor, MI, USA \\ d University of Miami, Miami, FL, USA \\ e Kent State University, Kent, OH, USA
}

\section{A R T I C L E I N F O}

Article history:

Available online 28 July 2008

\section{Keywords:}

Israel

War

Trauma

Post-traumatic stress disorder (PTSD)

Risk factors

Resilience factors

Israel-Hezbollah War

Mental health

\begin{abstract}
A B S T R A C T
Although there is abundant evidence that mass traumas are associated with adverse mental health consequences, few studies have used nationally representative samples to examine the impact of war on civilians, and none have examined the impact of the Israel-Hezbollah War, which involved unprecedented levels of civilian trauma exposure from July 12 to August 14, 2006. The aims of this study were to document probable post-traumatic stress disorder (PTSD), determined by the PTSD Symptom Scale and selfreported functional impairment, in Jewish and Arab residents of Israel immediately after the Israel-Hezbollah War and to assess potential risk and resilience factors. A telephone survey was conducted August 15-October 5, 2006, following the cessation of rocket attacks. Stratified random sampling methods yielded a nationally representative population sample of 1200 adult Israeli residents. The rate of probable PTSD was $7.2 \%$. Higher risk of probable PTSD was associated with being a woman, recent trauma exposure, economic loss, and higher psychosocial resource loss. Lower risk of probable PTSD was associated with higher education. The results suggest that economic and psychosocial resource loss, in addition to trauma exposure, have an impact on post-trauma functioning. Thus, interventions that bolster these resources might prove effective in alleviating civilian psychopathology during war.
\end{abstract}

(c) 2008 Elsevier Ltd. All rights reserved.
Following a 5-year period of ongoing terrorism during the Al Aqsa Intifada, Israel experienced an unprecedented series of rocket attacks from Hezbollah in Lebanon. During the period from July 12 to August 14, 2006, nearly 4000

\footnotetext{
is This work was supported in part by an Ohio Board of Regents Research Challenge grant and a grant from the National Institute of Mental Health (RO1-MH07687). The funding organizations did not play a role in the design and conduct of the study, collection, management, analysis, and interpretation of the data, or preparation, review, or approval of the manuscript.

* Corresponding author. Summa Health System, Psychiatry, St. Thomas Hospital, 4th Floor, Ambulatory Care Building, 444 North Main Street, Akron, OH 44310, USA. Tel.: +1330379 9081.

E-mail address: palmierp@summa-health.org (P.A. Palmieri).
}

rockets fell on Northern Israel and threatened areas as far south as the main population centers of Tel Aviv (Arkin, 2006). More than 300,000 Israelis evacuated Northern Israel and more than 1,000,000 lived in air-raid shelters for this period (Israeli Ministry of Foreign Affairs, 2006). Work and social life were severely disrupted as only evacuation or shelters were safe. Perhaps most disconcerting to Israelis, the Israel Defense Forces, who are often seen as nearly infallible, were unable to cause a cessation of the attacks, or even limit their frequency. This has been interpreted by many Israelis as a critical weakness in the defensive shield upon which they depend for their very survival (Feldman, 2006). 
Few studies have examined the impact of war on civilian populations, and to our knowledge no study examined a nationally representative sample of a country that had actually been under active attack. Rates of depression were found to be elevated in Lebanese communities that sustained a high degree of exposure to the Lebanon Wars, even after controlling for pre-war depression (Karam et al., 1998). Rates of PTSD and general psychiatric morbidity among residents of Southern Lebanese communities that were occupied until 2000 were still elevated 5 years later (Farhood, DiMassi, \& Lehtinen, 2006). Studies on national samples during the Israel-Lebanon War in 1980 (Hobfoll, Lomranz, Eyal, Bridges, \& Tzemach, 1989) and the first Gulf war in Israel in 1990 (Lomranz, Hobfoll, Johnson, Eyal, \& Tzemach, 1994) found greatly heightened levels of depressive mood that quickly declined with the resolution of conflict; however, although there was threat to the civilian population and fear of harm to loved ones who served in the armed forces during these first two wars, there were few incursions into Israel proper in these conflicts beyond the fall of a few errant rockets. The 2006 crisis was quite different, in that it followed a 5-year period of terrorist threat with over 100 suicide bomber attacks in Israel, resulting in nearly 1000 deaths and 5000 injuries to Israeli civilians (National Security Studies Center Terrorism Database, 2007). Further, unlike periods of earlier wars, the 2006 crisis involved rocket attacks that were unprecedented and allowed virtually no warning time to seek shelter, hence forcing citizens to stay in shelters or evacuate. These aspects of the 2006 war are particularly salient because recent research on terrorism has suggested that psychopathology after war, including post-traumatic stress disorder (PTSD), is particularly prevalent when people face threat of death or serious injury (Bleich, Gelkopf, \& Solomon, 2003; Galea et al., 2002; Silver, Holman, McIntosh, Poulin, \& Gil-Rivas, 2002) and when their daily routines are significantly disrupted (Shalev, Tuval, Frenkiel-Fishman, Hadar, \& Eth, 2006).

In this paper we examined factors associated with risk and resilience among Israeli citizens-including both Jews and Arabs-in the immediate aftermath of the 2006 Israel-Hezbollah War. Multiple studies have demonstrated several demographic factors that confer higher risk of PTSD among trauma exposed individuals, including female gender, minority status, younger age, lower education, and lower socioeconomic status (see Brewin, Andrews, \& Valentine, 2000, for a meta-analysis). There also is evidence from other Israeli samples that traditionally (moderately) religious have a higher risk of PTSD than either secular or very religious individuals (Hobfoll, Canetti-Nisim, \& Johnson, 2006; Hobfoll et al., 2008). Degree of trauma exposure is another strong predictor of PTSD, with higher levels of exposure associated with higher risk of PTSD (Brewin et al., 2000). In addition to trauma exposure, more economic loss and more psychosocial resource loss have been found to sharply increase risk of PTSD (Galea et al., 2008; Hobfoll, Canetti-Nisim, et al., 2006). More social support, on the other hand, is a well known protective factor against PTSD (Brewin et al., 2000). Similarly, a higher level of self-efficacy is thought to reduce risk of PTSD (Benight \& Bandura, 2004). The effects of post-traumatic growth are not as clear; more "growth" has been found to be a risk factor (Hobfoll, Canetti-Nisim, et al., 2006) and a protective factor (Frazier, Conlon, \& Glaser, 2001; Hall et al., 2008) for PTSD. In particular, we were concerned with documenting the role for potentially modifiable factors that could suggest areas for future intervention.

\section{Methods}

\section{Sampling}

We recruited the sample using random selection from comprehensive lists based on the Israeli telephone company (Bezeq) database of landline telephone numbers (which contains approximately $98 \%$ of the telephone numbers in Israel), stratified by sociodemographic variables (geographical area, level of religiosity, and socioeconomic level) to insure a nationally representative sample of adult (18 years of age and older) Israelis. A total of 3788 phone numbers (households) were called; 927 (24.5\%) were deemed to be irrelevant because they were disconnected or were business or fax numbers. Of the 2861 relevant numbers, 390 (13.6\%) were unanswered after five calls; 179 (6.3\%) were answered by someone who didn't speak Hebrew, Russian, or Arabic; and 2292 (80.1\%) were answered by someone who could communicate in Hebrew, Russian, or Arabic. Of these 2292 usable connections, 1025 (44.7\%) individuals refused to participate; 67 (2.9\%) partially completed the questionnaire; and 1200 fully completed it, yielding a final response rate of $52.4 \%$ of usable connections, or $41.9 \%$ of relevant numbers.

\section{Data collection}

Surveys were administered by native or fluent speakers in Hebrew, Russian, or Arabic following the cessation of the 2006 rocket attacks, between August 15 and October 5, 2006. Over $96 \%$ of the 1200 surveys were completed within 15 min. Informed consent was obtained at the outset of the phone call. The study was approved by the institutional review boards of Kent State University and the University of Haifa.

\section{Instruments}

The survey instruments were prepared in Hebrew and translated and back-translated into Russian and Arabic. Domains in this instrument all have been used in prior research where they were found to have good reliability and construct validity (Hobfoll, Canetti-Nisim, et al., 2006).

\section{Sample characteristics}

The following demographic variables were assessed: sex (male, female), ethnicity (Jewish, Arab), marital status (single/divorced/separated/widowed, married/cohabitating), age $(18-25,26-35,36-50,51-65,66+$ years), education (less than high school, high school graduate, more than high school, college graduate), income (low: much lower than average or a little lower than average; medium: average; high: a little higher than average or much higher than 
average), religiosity (secular, traditional, religious, ultrareligious).

\section{Exposure and major life stress indicators}

Recent exposure to terrorist/rocket attacks was assessed with four items that asked participants whether they experienced the following in recent months: (a) a death of a family member or friend in a rocket/terrorist attack, (b) an injury to oneself, a family member, or a friend in a rocket/ terrorist attack, (c) a period of time when you feared for the life of someone close to you after a rocket/terrorist attack (phones only work for several minutes and can take hours to be restored after a terrorist or rocket attack, frequently leading to a sense of panic if a loved one is believed to be in the vicinity of an attack), and (d) whether they witnessed or were present at a rocket/terrorist attack site where there were injuries or fatalities. The number of endorsed items was trichotomized to reflect 0,1 , or more than 1 type of recent exposure. Internal reliability was not calculated because each type of traumatic experience is discrete and is not necessarily expected to predict other types of exposure. Given that Northern Israel was primarily threatened by rocket attacks, we assessed proximity to the rocket attacks by asking respondents whether they resided in Northern Israel or elsewhere.

We were particularly interested in the impact of trauma-related exposure to the current crisis, but measured past exposure and other major life stressors in the past year in order to isolate the impact of current exposure. Prior trauma exposure was measured with a single item that asked whether the individual had "ever experienced a war or terrorist-related event where your life was in danger". Stressful (non-traumatic) life events from the past 12 months were assessed with five items asking about (a) serious illness or injury starting or worsening, (b) household member being unemployed for more than 3 months, (c) serious financial problems, (d) death of someone close to you, and (e) family or relationship problems. The number of endorsed items was trichotomized to indicate 0,1 , or more than 1 type of non-traumatic stressor exposure. As with the other exposure variables, an internal consistency estimate is not appropriate for this measure. Measures of exposure to past traumas and non-traumatic stressors were used as control variables when examining the influence of recent trauma exposure on probable PTSD.

To measure economic loss, participants were asked two items to determine whether, in recent months, they (a) suffered economically as a result of a rocket/terrorist attack, and (b) suffered property damage as a result of a rocket/terrorist attack. The recent economic loss variable indicated 0,1 , or 2 types of economic loss. As with the trauma exposure scales, internal reliability was not calculated for the economic loss scale because the types of economic loss are discrete.

Psychosocial resource loss related to recent terrorist/ rocket attacks was assessed with seven items from the Conservation of Resources - Evaluation (COR-E; Hobfoll \& Lilly, 1993) (e.g., "There is at least one person whom you know that you like less than you used to because of things that occurred between you", "You became less confident in your own abilities to cope with major crises"). This scale previously has been used in studies of terrorism in Israel
(Hobfoll, Canetti-Nisim, et al., 2006) and in the United States (Norris, 2001) and found to be predictive of PTSD. Respondents rated their extent of loss on a 4-point scale. Item responses were summed so that higher scores reflected more loss. As with the exposure and economic loss measures, Cronbach's alpha is not appropriate for these items, as one type of loss does not necessarily portend others.

\section{Potential resilience indicators}

Post-traumatic growth following the terrorist and rocket attacks was assessed with six items from the CORE (Hobfoll \& Lilly, 1993). Respondents were asked to what extent they experienced various positive changes in response to the terrorist and rocket attacks (e.g., "increased feeling of intimacy with your family", "increased sense of meaning"). Respondents rated items on a 4-point scale. Item responses were summed to represent the total amount of post-traumatic growth related to the attacks, with higher scores indicating more growth $(\alpha=0.75)$.

Self-efficacy was assessed with 10 items (Zeidner, Schwarzer, \& Jerusalem, 1993) (e.g., "I can always manage to solve difficult problems if I try hard enough", "I am confident that I could deal efficiently with unexpected events"). Respondents indicated how true each statement was on a 4-point scale. Summed responses yielded a total score, with higher scores reflecting higher levels of self-efficacy $(\alpha=0.87$ ). Due to a highly negatively skewed distribution, a square-transformed variable was used for statistical analyses.

Satisfaction with social support was assessed with three items from the Support Satisfaction Questionnaire (Sarason, Sarason, Shearin, \& Pierce, 1987) that asked "How satisfied are you with the social support you receive from (your spouse/partner; family; friends)." Respondents rated each item on a 4-point scale. Responses were summed to yield a scale score $(\alpha=0.68)$. Because this variable was highly negatively skewed even after different transformations were applied, it was trichotomized into low (0-6), medium (7-8), and high (9) support.

\section{Probable PTSD}

Current PTSD symptoms were assessed with the PTSD Symptom Scale (Foa, Riggs, Dancu, \& Rothbaum, 1993), a commonly used measure with good psychometric properties with a variety of populations, including in a previous study with this general population (Hobfoll, Canetti-Nisim, et al., 2006). It consists of 17 items that correspond to the DSM-IV diagnostic criteria for PTSD; five items assess re-experiencing symptoms, seven assess avoidance/numbing symptoms, and five assess hyperarousal symptoms. Respondents rated each item on a 4-point scale based on the past month $(\alpha=0.91)$. Items rated two (moderate severity) or higher were considered to be clinically significant symptoms. The DSM-IV scoring algorithm was followed to determine whether the endorsed items satisfied the symptom criteria for PTSD (Criteria B, C, and D). We also added a single item to ask whether feelings and thoughts about rocket/terrorist attacks interfered with routine functioning at home or at work. Respondents meeting full symptom criteria and reporting impaired functioning were classified as probable PTSD cases. 
Statistical analyses

Univariate descriptive statistics were computed for sample characteristics (sex, ethnicity, marital status, age, education, income, religiosity), exposure/stressor indicators (recent trauma exposure, proximity to the general vicinity of rocket attacks, past trauma exposure, nontraumatic stressors, economic loss, psychosocial resource loss), potential resilience indicators (traumatic growth, self-efficacy, social support), and probable PTSD. Bivariate associations between probable PTSD and each of the other variables were assessed with two-tailed Pearson chi-square tests, Fisher's exact tests, or independent sample $t$-tests. Variables with $P$-values $<0.1$ were included in a simultaneous multivariate logistic regression model with probable PTSD as the dependent variable, in order to evaluate the significance of each predictor after controlling for the other predictors. All analyses were conducted with SPSS 13.0.

\section{Results}

Univariate analyses

Sample demographics are provided in Table 1. There were no statistical differences between the current sample and the 2003 Census in terms of sex, ethnicity, age, and education. The sample was composed of 621 women (51.8\%) and 579 men (48.3\%). There were 960 Jews (80.0\%) and 240 Arabs (20.0\%). The mean age was 42.9 years (SD, 16.7; range $=18-95)$. Classifying by age group, $199(18.4 \%)$ were 18 -25 years, 215 (19.9\%) were $26-35$ years, 318 (29.4\%) were $36-50$ years, 230 (21.3\%) were 51-65 years, and 120 (11.1\%) were over 65 years old. Regarding education level, 167 (14.0\%) did not complete high school, 494 (41.2\%) completed high school, 253 (21.2\%) finished some college, and $282(23.6 \%)$ completed college. With respect to income, 521 (48.5\%) reported below average monthly household income, $272(25.3 \%)$ reported average income (approximately $\$ 8500)$, and $282(26.2 \%)$ reported above average income. There were 778 (65.3\%) married/cohabitating respondents and $414(34.7 \%)$ single respondents (never married, divorced, separated, widowed). In terms of religiosity, 472 (40.3\%) self-identified as secular, 425 (36.3\%) as traditional, $200(17.1 \%)$ as religious, and $73(6.2 \%)$ as ultra-religious.

\section{Terrorism and war exposure and major life stress}

Main results of univariate analyses are included in Table 1. Two-thirds of the sample $(67.1 \%)$ reported experiencing recently at least one type of terrorist- or rocket-related traumatic event; one-fourth $(26.3 \%)$ reported more than 1 type. By far the most commonly reported type was experiencing a period of time following a terrorist or rocket attack when one feared for the life of someone close to the respondent (62.4\%). Other recent traumas occurred at the following rates: being present at the site of an attack where there were injuries or fatalities (20.5\%), experiencing an injury to oneself, a family member, or a friend in a terrorist or rocket attack (10.4\%), and experiencing a death of a family member or friend in such an attack (9.4\%). In terms of proximity to rocket attacks, 380 (31.7\%) lived in Northern Israel, the area that sustained most of the attacks. With respect to prior trauma exposure, 379 (31.8\%) respondents reported experiencing a war or terrorist-related event where their lives were in danger. Regarding non-traumatic stressors, 740 (61.9\%) reported experiencing at least one in the past 12 months, including household member unemployed for more than 3 months (29.7\%), death of someone close to the respondent (28.5\%), serious financial problems (28.0\%), family or relationship problems (17.0\%), and serious illness or injury starting or worsening (11.4\%). A third of the sample (32.7\%) reported experiencing stressors in more than one of these categories.

Economic loss related to recent terrorist or rocket attacks was reported by $19.7 \%$ of the population; $16.8 \%$ reported one type of loss (suffering economically from an attack or suffering property damage from an attack) and $2.9 \%$ reported both types. The mean level of psychosocial resource loss was 8.78 (SD, 4.59).

\section{Potential resilience indicators}

Regarding resilience, mean levels of traumatic growth and self-efficacy were 8.45 (SD, 4.78) and 22.14 (SD, 5.52), respectively. For social support, the average item response was 1.58 (SD, 0.56) for the low group, 2.53 (SD, 0.15) for the medium group, and $3.00(\mathrm{SD}, 0.00)$ for the high group.

\section{Probable PTSD}

Probable PTSD was diagnosed in 86 (7.2\%) respondents based on DSM-IV symptom criteria (using the clinical cutoff of 2 [moderate severity] or higher on the $0-3$ scale) and the impairment item.

\section{Bivariate analyses}

Table 2 shows results of bivariate analyses of probable PTSD and the independent variables. Probable PTSD was significantly associated with several demographic variables, including sex (9.9\% female, $4.3 \%$ male; Fisher's exact test $P<0.001)$, income $(10.0 \%$ low income, $5.6 \%$ medium income, $5.0 \%$ high income; $\chi^{2}{ }_{2}=8.8 ; P=0.01$ ), education (14.0\% less than high school, $8.4 \%$ completed high school, $6.3 \%$ more than high school, $2.1 \%$ completed college; $\left.\chi_{3}^{2}=23.5 ; P<0.001\right)$, and religiosity (5.7\% secular, $8.3 \%$ traditional, $10.1 \%$ religious, $1.4 \%$ ultra-religious; $\chi^{2}{ }_{3}=8.4$; $P=0.04)$. Neither age nor marital status was associated with probable PTSD. Among the exposure and stress-related indicators, probable PTSD was significantly associated with non-traumatic stressful life events (5.7\% none, 4.9\% 1 type, $11.1 \% 2$ or more types; $\left.\chi^{2}{ }_{2}=13.0 ; P=0.002\right)$, recent trauma exposure (3.1\% none, $8.6 \% 1$ type, $10.2 \% 2$ or more types; $\left.\chi_{2}^{2}=15.7 ; \quad P<0.001\right)$, proximity to the rocket attacks (5.7\% lived outside Northern Israel, 10.5\% lived in Northern Israel; Fisher's exact test $P=0.004)$, recent economic loss (6.2\% none, 9.5\% 1 type, 22.9\% 2 types; $\left.\chi_{2}^{2}=16.0 ; P<0.001\right)$, and psychosocial resource loss $(M=8.47$ [SD, 4.47] for the no PTSD group, $M=12.52$ [SD, 4.55] for the probable PTSD group; $t=-8.04$, $\mathrm{df}=1172$; $P<0.001)$ in the expected directions, but was not associated with past trauma exposure. With regard to potential resilience indicators, probable PTSD was significantly associated with traumatic growth $(M=8.29$ [SD, 4.79] for the no PTSD group, $M=10.48$ [SD, 4.08] for the probable 
Table 1

Sample characteristics $(N=1200)$

\begin{tabular}{|c|c|c|}
\hline Variable & No. ${ }^{\mathrm{a}}(\%)$ & $M(\mathrm{SD})$ \\
\hline \multicolumn{3}{|l|}{ Demographic indicators } \\
\hline \multicolumn{3}{|l|}{ Sex } \\
\hline Male & $579(48.3)$ & \\
\hline Female & $621(51.8)$ & \\
\hline \multicolumn{3}{|l|}{ Ethnicity } \\
\hline Jew & $960(80.0)$ & \\
\hline Arab & $240(20.0)$ & \\
\hline \multicolumn{3}{|l|}{ Age } \\
\hline $18-25$ & $199(18.4)$ & \\
\hline $26-35$ & $215(19.9)$ & \\
\hline $36-50$ & $318(29.4)$ & \\
\hline $51-65$ & $230(21.3)$ & \\
\hline $66+$ & $120(11.1)$ & \\
\hline \multicolumn{3}{|l|}{ Marital status } \\
\hline $\begin{array}{l}\text { Single/divorced/separated/ } \\
\text { widowed }\end{array}$ & $414(34.7)$ & \\
\hline Married/cohabitating & $778(65.3)$ & \\
\hline \multicolumn{3}{|l|}{ Education } \\
\hline Less than high school & $167(14.0)$ & \\
\hline High school & $494(41.2)$ & \\
\hline More than high school & $253(21.2)$ & \\
\hline College & $282(23.6)$ & \\
\hline \multicolumn{3}{|l|}{ Income } \\
\hline Low & $521(48.5)$ & \\
\hline Medium & $272(25.3)$ & \\
\hline High & $282(26.2)$ & \\
\hline \multicolumn{3}{|l|}{ Religiosity } \\
\hline Secular & $472(40.3)$ & \\
\hline Traditional & $425(36.3)$ & \\
\hline Religious & $200(17.1)$ & \\
\hline Ultra-religious & $73(6.2)$ & \\
\hline \multicolumn{3}{|l|}{ Exposure/stress indicators } \\
\hline \multicolumn{3}{|c|}{ Non-traumatic stressful life events } \\
\hline No & $454(38.0)$ & \\
\hline Yes, 1 type & $349(29.2)$ & \\
\hline Yes, 2 or more types & $391(32.7)$ & \\
\hline \multicolumn{3}{|l|}{ Past trauma exposure } \\
\hline No & $811(68.2)$ & \\
\hline Yes & $379(31.8)$ & \\
\hline \multicolumn{3}{|l|}{ Recent trauma exposure } \\
\hline No & $394(32.8)$ & \\
\hline Yes, 1 type & $490(40.8)$ & \\
\hline Yes, 2 or more types & $316(26.3)$ & \\
\hline \multicolumn{3}{|l|}{ Proximity to rocket attacks } \\
\hline $\begin{array}{l}\text { Live outside Northern } \\
\text { Israel }\end{array}$ & $819(68.3)$ & \\
\hline Live in Northern Israel & $380(31.7)$ & \\
\hline \multicolumn{3}{|l|}{ Recent economic loss } \\
\hline No & $963(80.3)$ & \\
\hline Yes, 1 type & $201(16.8)$ & \\
\hline Yes, 2 types & $35(2.9)$ & \\
\hline Psychosocial loss & & $8.78(4.59)$ \\
\hline \multicolumn{3}{|l|}{ Potential resilience indicators } \\
\hline Traumatic growth & & $8.45(4.78)$ \\
\hline Self-efficacy & & $22.14(5.52)$ \\
\hline \multicolumn{3}{|l|}{ Social support } \\
\hline Low & $253(21.9)$ & \\
\hline Medium & $226(19.6)$ & \\
\hline High & $674(58.5)$ & \\
\hline
\end{tabular}

Table 1 (continued)

\begin{tabular}{lcc}
\hline Variable & No. $^{\text {a }(\%)}$ & $M(\mathrm{SD})$ \\
\hline Probable PTSD & $1109(92.8)$ & \\
No & $86(7.2)$ & \\
Yes & & \\
\hline
\end{tabular}

${ }^{a}$ Numbers within categories may not add up to 1200 for some variables due to missing values.

PTSD group; Welch's $t=-4.70, \mathrm{df}=103 ; P<0.001$ ), but not with self-efficacy or social support.

\section{Multivariate logistic regression analysis}

Variables associated with probable PTSD were included as predictors of probable PTSD in a simultaneous logistic regression model, in order to determine the relative importance of each predictor after controlling for all the other predictors. Results are provided in Table $3 .^{1}$ Significant demographic predictors of probable PTSD included sex (odds ratio $[\mathrm{OR}]=2.93 ; P<0.001$ for women compared to men) and education ( $\mathrm{OR}=0.19 ; P<0.01$ for completed college compared to less than a high school education). Among exposure/stress and potential resilience variables, significant predictors of probable PTSD included recent trauma exposure $(\mathrm{OR}=3.39 ; P<0.01$ for one type of recent trauma exposure compared to none; $\mathrm{OR}=3.05 ; P<0.05$ for two or more types of recent exposure compared to none), recent economic loss ( $\mathrm{OR}=3.69 ; P<0.05$ for two types of recent economic loss compared to none), and higher psychosocial resource loss $(\mathrm{OR}=1.27 ; P<0.001)$.

\section{Discussion}

We surveyed a national sample of Israelis in the weeks after the cessation of rocket attacks during the 2006 Israel-Hezbollah War. Overall exposure to recent rocket or terrorist attacks was high, with $67.1 \%$ of individuals reporting exposure to at least one type of event. Prevalence of probable PTSD was $7.2 \%$, slightly lower than that reported earlier by one national sample during another intense period of terrorism in Israel (9.4\%; Bleich et al., 2003), and virtually identical to that reported in the immediate aftermath of the attacks of September 11th, 2001 in Manhattan (7.5\%; Galea et al., 2002).

Among the demographic variables of interest, we found greater probable PTSD among women and lower probable PTSD among individuals with higher education. Women have often been found to have greater risk for PTSD following terrorism than men (Adams \& Boscarino, 2006; Bleich et al., 2003; Galea et al., 2002; Silver et al., 2002), and education has been noted as a resilience factor in some studies (Hobfoll, Canetti-Nisim, et al., 2006). Ethnicity, income, and religiosity were not significant independent predictors. One finding for religiosity, however, is worthy of note. Specifically, the ultra-religious had very low PTSD rates. This

\footnotetext{
${ }^{1}$ We also conducted a regression analysis using a continuous measure of post-traumatic stress symptoms as the dependent variable, and the results were very consistent in terms of the statistical significance of the predictor variables.
} 
Table 2

Bivariate associations between respondent characteristics and current probable PTSD $(N=1200)$

\begin{tabular}{|c|c|c|c|}
\hline Variable & $\begin{array}{l}\% \text { of }\left(n^{\mathrm{a}}\right) \\
\text { probable } \\
\text { PTSD }\end{array}$ & $M(\mathrm{SD})$ & $P$ value $^{\mathrm{b}}$ \\
\hline \multicolumn{4}{|l|}{ Demographic indicators } \\
\hline Sex & & & $<0.001$ \\
\hline Male & $4.3(578)$ & & \\
\hline Female & 9.9 (617) & & \\
\hline Ethnicity & & & 0.07 \\
\hline Jew & $6.5(956)$ & & \\
\hline Arab & $10.0(239)$ & & \\
\hline Age & & & 0.41 \\
\hline $18-25$ & 5.0 (199) & & \\
\hline $26-35$ & $5.6(215)$ & & \\
\hline $36-50$ & $7.9(318)$ & & \\
\hline $51-65$ & $9.3(227)$ & & \\
\hline $66+$ & $7.6(118)$ & & \\
\hline Marital status & & & 0.81 \\
\hline $\begin{array}{l}\text { Single/divorced/ } \\
\text { Separated/widowed }\end{array}$ & $7.5(412)$ & & \\
\hline Married/cohabitating & $7.1(775)$ & & \\
\hline Income & & & 0.01 \\
\hline Low & $10.0(519)$ & & \\
\hline Medium & $5.6(270)$ & & \\
\hline High & $5.0(282)$ & & \\
\hline Education & & & $<0.001$ \\
\hline $\begin{array}{l}\text { Less than } \\
\text { high school }\end{array}$ & $14.0(164)$ & & \\
\hline High school & $8.4(490)$ & & \\
\hline $\begin{array}{l}\text { More than } \\
\text { high school }\end{array}$ & $6.3(253)$ & & \\
\hline College & $2.1(282)$ & & \\
\hline Religiosity & & & 0.04 \\
\hline Secular & $5.7(471)$ & & \\
\hline Traditional & $8.3(423)$ & & \\
\hline Religious & 10.1 (199) & & \\
\hline Ultra-religious & $1.4(72)$ & & \\
\hline \multicolumn{4}{|l|}{ Exposure/stress indicators } \\
\hline $\begin{array}{l}\text { Non-traumatic stressful } \\
\text { life events }\end{array}$ & & & 0.002 \\
\hline No & $5.7(454)$ & & \\
\hline Yes, 1 type & $4.9(347)$ & & \\
\hline Yes, 2 or more types & $11.1(388)$ & & \\
\hline Past trauma exposure & & & 0.47 \\
\hline No & $6.8(809)$ & & \\
\hline Yes & $8.0(376)$ & & \\
\hline Recent trauma exposure & & & $<0.001$ \\
\hline No & $3.1(393)$ & & \\
\hline Yes, 1 type & $8.6(487)$ & & \\
\hline Yes, 2 or more types & $10.2(315)$ & & \\
\hline Proximity to rocket attacks & & & 0.004 \\
\hline $\begin{array}{l}\text { Live outside } \\
\text { Northern Israel }\end{array}$ & $5.7(814)$ & & \\
\hline Live in Northern Israel & $10.5(380)$ & & \\
\hline Recent economic loss & & & $<0.001$ \\
\hline No & 6.2 (959) & & \\
\hline Yes, 1 type & $9.5(200)$ & & \\
\hline Yes, 2 types & $22.9(35)$ & & \\
\hline Psychosocial loss & & & $<0.001$ \\
\hline & & $\begin{array}{l}8.47 \text { ( } 4.47) ; \\
\text { No PTSD }\end{array}$ & \\
\hline & & 12.52 (4.55); & \\
\hline & & Probable PTSD & \\
\hline
\end{tabular}

Table 2 (continued)

\begin{tabular}{|c|c|c|c|}
\hline Variable & $\begin{array}{l}\% \text { of }\left(n^{\mathrm{a}}\right) \\
\text { probable } \\
\text { PTSD }\end{array}$ & $M(\mathrm{SD})$ & $P$ value ${ }^{b}$ \\
\hline \multicolumn{4}{|c|}{ Potential resilience indicators } \\
\hline Traumatic growth & & $\begin{array}{l}8.29(4.79) ; \\
\text { No PTSD } \\
10.48(4.08) ; \\
\text { Probable PTSD }\end{array}$ & $<0.001$ \\
\hline Self-efficacy $^{c}$ & & $\begin{array}{l}22.26(5.42) ; \\
\text { No PTSD } \\
20.99 \text { (6.52); } \\
\text { Probable PTSD }\end{array}$ & 0.13 \\
\hline Social support & & & 0.13 \\
\hline Low & $9.2(251)$ & & \\
\hline Medium & $8.9(224)$ & & \\
\hline High & $5.9(674)$ & & \\
\hline
\end{tabular}

${ }^{a}$ Numbers within categories may not add up to total for some variables due to missing values.

b Chi-square tests, Fisher's exact tests, and independent sample $t$-tests (all two-tailed) were used to test for bivariate associations.

c Untransformed means and standard deviations are reported, but the $t$-test is based on square-transformed scores.

group is composed of individuals who essentially live in small, tightly knit spiritual communities that are somewhat secluded from the rest of Israeli society. Solomon and Berger (2005) found that in the face of war-like events, ultra-religious people cope by trusting God. They do not tend to consider a war-like situation as a matter of human control or of importance.

Although traumatic event exposure is typically considered a central predictor of psychopathology after trauma (Ozer, Best, Lipsey, \& Weiss, 2003), some studies of terrorism in Israel have not found this to be the case (Bleich et al., 2003). In our study, exposure and exposure-related stressors were also predictive of greater probable PTSD, controlling for other major life stressors and past war/ terrorism-related trauma. These included recent trauma exposure, greater economic loss, and greater psychosocial resource loss. This difference between our work and previous work may, in part, be explained by the fact that even at the height of the Al Aqsa Intifada examined by Bleich et al. (2003), most Israelis could adjust their lives and continue work, social lives, and school. Further, the chance of being killed in a terrorist attack, although great in an absolute sense, was about the same as being a traffic fatality (about 1 in 10,000). In contrast, a major segment of the population during the period of war we studied was directly exposed to the rocket attacks and their lives were meaningfully altered on an hour by hour basis. The disruption of daily lives due to war and terrorism has been found previously to be more critical than threat levels (Shalev et al., 2006). We note that although the attacks were in Northern Israel, most Israelis would have had exposed family members, wherever they personally lived, making the scope of the war truly national. None of the potential resilience indicators-traumatic growth, self-efficacy, and social support-were related to probable PTSD.

Consistent with work in the aftermath of the attacks of September 11th, 2001 in Manhattan (Bleich et al., 
Table 3

Multivariate associations (logistic regression odds ratios) between characteristics of the respondents and current probable PTSD $(N=1014)^{\mathrm{a}}$

\begin{tabular}{|c|c|}
\hline Predictors $^{\mathrm{b}}$ & OR $(95 \% \mathrm{CI})$ \\
\hline \multicolumn{2}{|l|}{ Demographic indicators } \\
\hline \multicolumn{2}{|l|}{ Ethnicity } \\
\hline Jewish & 1.00 \\
\hline Arab & $1.04(0.45-2.40)$ \\
\hline \multicolumn{2}{|l|}{ Sex } \\
\hline Male & 1.00 \\
\hline Female & $2.93(1.64-5.23)^{* * *}$ \\
\hline \multicolumn{2}{|l|}{ Income } \\
\hline Low & 1.00 \\
\hline Medium & $0.54(0.26-1.10)$ \\
\hline High & $0.56(0.27-1.17)$ \\
\hline \multicolumn{2}{|l|}{ Education } \\
\hline Less than high school & 1.00 \\
\hline High school & $0.68(0.35-1.35)$ \\
\hline More than high school & $0.50(0.22-1.14)$ \\
\hline College & $0.19(0.07-0.53)^{* *}$ \\
\hline \multicolumn{2}{|l|}{ Religiosity } \\
\hline Secular & 1.00 \\
\hline Traditional & $0.98(0.52-1.85)$ \\
\hline Religious & $1.88(0.83-4.22)$ \\
\hline Ultra-religious & $0.30(0.04-2.45)$ \\
\hline \multicolumn{2}{|l|}{ Exposure/stress indicators } \\
\hline \multicolumn{2}{|c|}{ Non-traumatic stressful life events } \\
\hline No & 1.00 \\
\hline Yes, 1 type & $0.71(0.34-1.47)$ \\
\hline Yes, 2 or more types & $0.95(0.49-1.82)$ \\
\hline \multicolumn{2}{|l|}{ Recent trauma exposure } \\
\hline No & 1.00 \\
\hline Yes, 1 type & $3.39(1.54-7.45)^{* *}$ \\
\hline Yes, 2 or more types & $3.05(1.28-7.23)^{*}$ \\
\hline \multicolumn{2}{|l|}{ Proximity to rocket attacks } \\
\hline Live outside Northern Israel & 1.00 \\
\hline Live in Northern Israel & $1.25(0.61-2.55)$ \\
\hline \multicolumn{2}{|l|}{ Recent economic loss } \\
\hline No & 1.00 \\
\hline Yes, 1 type & $1.22(0.63-2.34)$ \\
\hline Yes, 2 types & $3.69(1.21-11.21)^{*}$ \\
\hline Psychosocial loss & $1.27(1.18-1.36)^{* * *}$ \\
\hline \multicolumn{2}{|l|}{ Potential resilience indicator } \\
\hline Traumatic growth & $1.02(0.96-1.08)$ \\
\hline
\end{tabular}

Abbreviations: $\mathrm{PTSD}=$ post-traumatic stress disorder; $\mathrm{OR}=$ odds ratio; $\mathrm{CI}=$ confidence interval.

${ }^{*} P<0.05 ;{ }^{* *} P<0.01 ;{ }^{* * *} P<0.001$.

a Analysis was based on respondents with complete data for all variables in the analysis.

b Model includes predictors that were associated with probable PTSD status $(P<0.10)$.

2003; Hobfoll, Tracy, \& Galea, 2006) and in Israel during the Al Aqsa Intifada period of terrorism (Hobfoll, Canetti-Nisim, et al., 2006), we found a marked relation between economic and psychosocial resource loss and the risk of probable PTSD. Despite these findings, and earlier ones on a similar marked impact of psychosocial and material resource loss on psychological distress following disaster (Benight, Freyaldenhoven, Hughes, Ruiz, \& Zoschke, 2000; Benight et al., 1999; Freedy, Shaw, Jarrell, \& Masters, 1992; Ironson et al., 1997; Norris \& Kaniasty, 1996), dominant theories concerning the etiology of PTSD do not include resource loss as a major factor (Brewin \& Holmes, 2003).

Although some recent theoretical work has suggested that the experience of trauma may be associated with post-traumatic growth that is salutary (Tedeschi \& Calhoun, 1995, 2004), the current bivariate and multivariate results and some other recent empiric work (Helgeson, Reynolds, \& Tomich, 2006; Hobfoll, Canetti-Nisim, et al., 2006) suggest that this does not appear to be the consistent case. Combined, these recent studies suggest that traumatic growth in the case of war and terrorism may reflect a kind of wishful thinking or a way of dealing with PTSD symptoms, or may reflect that as people become more distressed they seek more growth. Without prospective study it is not possible to determine whether this might in the long run be beneficial, undermining, or neither.

It is interesting that post-traumatic growth, self-efficacy, and social support did not emerge as resilience factors in this study. It has been suggested that resilience factors are more important during recovery than in the immediate phase of confrontation with danger and serious challenge (Benight et al., 1999; Hobfoll, 1998; Hobfoll \& London, 1986; Sumer, Karanci, Berument, \& Gunes, 2005; Tedeschi \& Calhoun, 2004). Perhaps insufficient time had elapsed from the end of the rocket attacks to the time of the survey for changes in these resilience factors to occur or for their protective effects to take hold.

\section{Limitations}

Several considerations are important for interpretation of this study. First, without knowing the pre-Intifada baseline level of PTSD in the population, we can only infer that war and terrorism have resulted in increased PTSD prevalence. Second, it is possible that the respondents in this sample differed in some way from the general population of Israel. In this regard, the reasonable response rate and the similarity between our sample and expected population demographics are reassuring. Third, we used phone interviews to assess current PTSD symptoms. Although telephone and in-person interviews generally result in comparable estimates of symptomatology, probable PTSD is not equivalent to PTSD that is formally diagnosed through clinical assessment. Thus, comparisons between the current results and those from studies using more formal assessment methods should be made with caution. Fourth, we did not explicitly measure peritraumatic emotional and cognitive reactions that are related to PTSD (e.g., DSM-IV PTSD Criterion A2: experiencing intense fear, helplessness, or horror in response to the event), though it seems reasonable to assume that someone who is directly or indirectly experiencing rocket attacks would report at least one of these reactions. Fifth, we did not assess all potentially important factors, such as prior psychiatric history, that might moderate the impact of other vulnerability and resilience factors.

\section{Conclusions and recommendations}

Our findings suggest that the factors that confer risk or resilience during war are neither obvious nor necessarily 
intuitive. Vulnerability and resilience factors affect impact differently depending upon contextual factors, time since exposure and duration of exposure, past experience with war, and belief systems (Somer, Ruvio, Soref, \& Sever, 2005). Our findings suggest some of that complexity and encourage the importance of future study of war in different time frames, contexts, and for different ethnic groups.

Given the growing evidence for the impact of both economic and psychosocial resource loss as among the strongest predictors of probable PTSD in this and other studies, clinicians should assess for them accordingly as part of their interview or screening assessments. Furthermore, interventions such as psychological first aid, that among other things are designed to bolster such resources, might prove effective in reducing the severity of posttrauma reactions. Finally, given the evidence that psychological distress decreases for many naturally after mass trauma (Galea et al., 2003), this study suggests that it might be appropriate to limit individual treatment after war strictly to supportive therapy, and to efforts that may encourage the development of natural resilience.

\section{References}

Adams, R. E., \& Boscarino, J. A. (2006). Predictors of PTSD and delayed PTSD after disaster: the impact of exposure and psychosocial resources. Journal of Nervous and Mental Disease, 194, 485-493.

Arkin, W. M. (2006). Facts and myths about the Israel-Hezbollah war. Early Warning. Available from. http://blog.washingtonpost.com/earlywarning/2006/09.

Benight, C. C., \& Bandura, A. (2004). Social cognitive theory of post-traumatic recovery: the role of perceived self-efficacy. Behaviour Research and Therapy, 42, 1129-1148.

Benight, C. C., Freyaldenhoven, R. W., Hughes, J., Ruiz, J. M., \& Zoschke, T. A. (2000). Coping self-efficacy and psychological distress following the Oklahoma City bombing. Journal of Applied Social Psychology, 30, 1331-1344.

Benight, C. C., Ironson, G., Klebe, K., Carver, C. S., Wynings, C., Burnett, C. S., et al. (1999). Conservation of resources and coping self-efficacy predicting distress following a natural disaster: a causal model analysis where the environment meets the mind. Anxiety, Stress, and Coping, $12,107-126$.

Bleich, A., Gelkopf, M., \& Solomon, Z. (2003). Exposure to terrorism, stress-related mental health symptoms, and coping behaviors among a nationally representative sample in Israel. Journal of the American Medical Association, 290, 612-620.

Brewin, C. R., Andrews, B., \& Valentine, J. D. (2000). Meta-analysis of risk factors for posttraumatic stress disorder in trauma-exposed adults. Journal of Consulting and Clinical Psychology, 68, 748-766.

Brewin, C. R., \& Holmes, E. A. (2003). Psychological theories of post-traumatic stress disorder. Clinical Psychology Review, 23, 339-376.

Farhood, L., DiMassi, H., \& Lehtinen, T. (2006). Exposure to war-related traumatic events, prevalence of PTSD, and general psychiatric morbidity in a civilian population from Southern Lebanon. Journal of Transcultural Nursing, 17, 333-340.

Feldman, S. (2006). The Hezbollah-Israel War: a preliminary assessment. Middle East Brief, 10, 1-7.

Foa, E. B., Riggs, D. S., Dancu, C. V., \& Rothbaum, B. O. (1993). Reliability and validity of a brief instrument for assessing post-traumatic stress disorder. Journal of Traumatic Stress, 6, 459-473.

Frazier, P., Conlon, A., \& Glaser, T. (2001). Positive and negative life changes following sexual assault. Journal of Consulting and Clinical Psychology, 69, 1048-1055.

Freedy, J. R., Shaw, D. L., Jarrell, M. P., \& Masters, C. R. (1992). Towards an understanding of the psychological impact of natural disasters: an application of the conservation of resources stress model. Journal of Traumatic Stress, 5, 441-454.

Galea, S., Ahern, J., Resnick, H., Kilpatrick, D., Bucuvalas, M., Gold, J., et al. (2002). Psychological sequelae of the September 11 terrorist attacks in New York City. New England Journal of Medicine, 346, 982-987.
Galea, S., Ahern, J., Tracy, M., Hubbard, A., Cerda, M., Goldmann, E., et al. (2008). The determinants of post-traumatic stress in a populationbased cohort study. Epidemiology, 19, 47-54.

Galea, S., Vlahov, D., Resnick, H., Ahern, J., Susser, E., Gold, J., et al. (2003). Trends of probable post-traumatic stress disorder in New York City after the September 11th terrorist attacks. American Journal of Epidemiology, 158, 514-524.

Hall, B. J., Hobfoll, S. E., Palmieri, P. A., Canetti-Nisim, D., Shapira, O., Johnson, R. J., et al. (2008). The psychological impact of impending forced settler disengagement in Gaza: trauma and post-traumatic growth. Journal of Traumatic Stress, 21, 22-29.

Helgeson, V. S., Reynolds, K. A., \& Tomich, P. L. (2006). A meta-analytic review of benefit finding and growth. Journal of Consulting and Clinical Psychology, 74, 797-816.

Hobfoll, S. E. (1998). Stress, culture, and community: The psychology and philosophy of stress. New York, NY: Plenum.

Hobfoll, S. E., Canetti-Nisim, D., \& Johnson, R. (2006). Exposure to terrorism, stress-related mental health symptoms, and defensive coping among Jews and Arabs in Israel. Journal of Consulting and Clinical Psychology, 74, 207-218.

Hobfoll, S. E., Canetti-Nisim, D., Johnson, R. J., Varley, J., Palmieri, P. A., \& Galea, S. (2008). The association of exposure, risk and resiliency factors with PTSD among Jews and Arabs exposed to repeated acts of terrorism in Israel. Journal of Traumatic Stress, 21, 9-21.

Hobfoll, S. E., \& Lilly, R. S. (1993). Resource conservation as a strategy for community psychology. Journal of Community Psychology, 21, 128-148.

Hobfoll, S. E., Lomranz, J., Eyal, N., Bridges, A., \& Tzemach, M. (1989). Pulse of a nation: depressive mood reactions of Israelis to the Israel-Lebanon War. Journal of Personality and Social Psychology, 56, 1002-1012.

Hobfoll, S. E., \& London, P. (1986). The relationship of self-concept and social support to emotional distress among women during war. Journal of Social and Clinical Psychology, 4, 189-203.

Hobfoll, S. E., Tracy, M., \& Galea, S. (2006). The impact of resource loss and "traumatic growth" on probable PTSD and depression following terrorist attacks. Journal of Traumatic Stress, 19, 867-878.

Ironson, G., Wynings, C., Schneiderman, N., Baum, A., Rodriguez, M., Greenwood, D., et al. (1997). Post-traumatic stress symptoms, intrusive thoughts, loss, and immune function after Hurricane Andrew. Psychosomatic Medicine, 59, 128-141.

Israeli Ministry of Foreign Affairs. (2006). http://www.mfa.gov.il/mfa/ home.asp. Accessed 15.02.07.

Karam, E. G., Howard, D. B., Karam, A. N., Ashkar, A., Shaaya, M., Melhem, N., et al. (1998). Major depression and external stressors: the Lebanon Wars. European Archives of Psychiatry and Clinical Neuroscience, 248, 225-230.

Lomranz, J., Hobfoll, S. E., Johnson, R., Eyal, N., \& Tzemach, M. (1994). A nation's response to attack: Israelis' depressive reactions to the Gulf War. Journal of Traumatic Stress, 7, 59-63.

National Security Studies Center Terrorism Database. (2007). Terrorism research: the terrorism project. Available from. http://nssc.haifa.ac. il/Terror/index.html.

Norris, F. H. (2001). Measuring exposure to the events of September 11, 2001: pretest results and stress/loss norms obtained from a minimally exposed but diverse sample of college students. Available from. http://obssr.od.nih.gov/Documents/About_OBSSR/Activities/norris\% 209-11\%20pilot\%20results.doc.

Norris, F. H., \& Kaniasty, K. (1996). Received and perceived social support in times of stress: a test of the social support deterioration deterrence model. Journal of Personality and Social Psychology, 71, 498-511.

Ozer, E. J., Best, S. R., Lipsey, T. L., \& Weiss, D. S. (2003). Predictors of posttraumatic stress disorder and symptoms in adults: a meta-analysis. Psychological Bulletin, 129, 52-73.

Sarason, I. G., Sarason, B. R., Shearin, E. N., \& Pierce, G. R. (1987). A brief measure of social support: practical and theoretical implications. Journal of Social and Personal Relationships, 4, 497-510.

Shalev, A. Y., Tuval, R., Frenkiel-Fishman, S., Hadar, H., \& Eth, S. (2006). Psychological responses to continuous terror: a study of two communities. American Journal of Psychiatry, 163, 667-673.

Silver, R. C., Holman, E. A., McIntosh, D. N., Poulin, M., \& Gil-Rivas, V. (2002). Nationwide longitudinal study of psychological responses to September 11. Journal of the American Medical Association, 288, 1235-1244.

Solomon, Z., \& Berger, R. (2005). Coping with the aftermath of terror: resilience of ZAKA body handlers. Journal of Aggression, Maltreatment, $\mathcal{E}$ Trauma, 10, 593-604.

Somer, E., Ruvio, A., Soref, E., \& Sever, I. (2005). Terrorism, distress and coping: high versus low impact regions and direct versus indirect civilian exposure. Anxiety, Stress, and Coping, 18, 165-182. 
Sumer, N., Karanci, A. N., Berument, S. K., \& Gunes, H. (2005). Personal resources, coping self-efficacy, and quake exposure as predictors of psychological distress following the 1999 earthquake in Turkey. Journal of Traumatic Stress, 18, 331-342.

Tedeschi, R. G., \& Calhoun, L. G. (1995). Trauma and transformation: Growing in the aftermath of suffering. Thousand Oaks, CA: Sage.
Tedeschi, R. G., \& Calhoun, L. G. (2004). Posttraumatic growth: conceptual foundations and empirical evidence. Psychological Inquiry, 15, $1-18$.

Zeidner, M., Schwarzer, R., \& Jerusalem, M. (1993). Hebrew adaptation of the general self-efficacy scale. Health Psychology, 12, 102-104. 